\title{
The effect of nylon nanofibers on the dynamic behaviour and the delamination resistance of GFRP composites
}

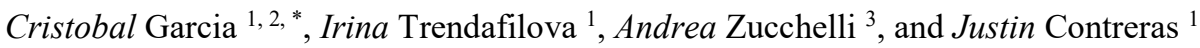 \\ ${ }^{1}$ University of Strathclyde, Department of Mechanical and Aerospace Engineering, 75 Montrose Street, G1 1XJ, Glasgow, UK \\ ${ }^{2}$ IMDEA Materials Institute, C/ Eric Kandel 2, 28906, Getafe, Spain \\ ${ }^{3}$ University of Bologna, Department of Industrial Engineering, Viale Risorgimento 2, 40125, Bologna, Italy
}

\begin{abstract}
Vibrations are responsible for a considerable number of accidents in aircrafts, bridges and other civil engineering structures. Therefore, there is a need to reduce the vibrations on structures made of composite materials. Delamination is a particularly dangerous failure mode for composite materials because delaminated composites can lose up to $60 \%$ of their strength and stiffness and still remain unchanged. One of the methods to suppress vibrations and preventing delamination is to incorporate nanofibers into the composite laminates. The aim of the present work is to investigate how nylon nanofibers affect the dynamic behaviour and delamination resistance of glass fibre reinforced polymer (GFRP) composites. Experiments and numerical simulations using finite element modelling (FEM) analysis are used to estimate the natural frequencies, the damping ratio and inter-laminar strength in GFRP composites with and without nylon nanofibers. It is found that the natural frequencies of the nylon nano-modified composites do not change significantly as compared to the traditional composites. However, nano-modified composites demonstrated a considerable increase in damping ratio and inter-laminar shear strength due to the incorporation of nylon nanofibers. This work contributes to the knowledge about the mechanical and dynamic properties of glass fibre reinforced polymer (GFRP) composites with nylon nanofibers.
\end{abstract}

\section{Introduction}

Composite laminates interleaved with nanofibers has become rather popular recently because the inclusion of nanofibers can enhance some material properties drastically. One of the most frequent failure modes in composite materials is delamination. Delamination is difficult to detect because it takes place and grows under the surface without being visible from outside and it may cause catastrophic failure in the whole structure. One of the methods to prevent delamination is the introduction of nanofibers into epoxy-based composite laminate materials [1]. Composites interleaved with nanofibers are supposed to increase their delamination resistance as compared to the virgin ones [2]. The interleaving with nano-fibers can be also used to increase the stiffness and other macro-properties of epoxy-based composite laminates.

Vibrations are one of the most common and important motions of most mechanical, civil and aerospace structures. Vibrations can directly and adversely affect the working condition and the health of machines and structures. In such a sense vibration analysis is of critical importance for purposes of equipment maintenance and environmental safety. Vibrations are responsible for a considerable number of failures in structures made of composite materials including aircrafts, buildings and bridges failures. The interleaving with nano-fibres of composite laminates can be also used for purposes of vibration amplitude reduction. Thus several studies suggest the inclusion of nylon nanofibers in composite laminates with the aim of improving its properties $[3,4]$. It should be said that on the other hand very little is known about the effect of nylon interleaving on the macro properties of the resulting composite including its dynamics and vibratory behaviour. There are only a couple of studies that consider the dynamic behaviour of nano-interleaved composite laminates [5].

Delamination is known to be one of the most dangerous and in the same time widespread damage and failure mode. Delamination affects the vibratory behaviour of laminates and thus vibrations can be useful delamination diagnosis [6]. From such a view point this study also investigated the delamination resistance of nylon interleaved GFRP laminates.

Nylon nanofibers fabricated by electrospinning are particularly suitable to improve the properties of composites because of their excellent properties which include high heat resistance, good adhesion with epoxy resin and excellent mechanical characteristics such as high tensile and flexural strength, stiffness and superior wear resistance compared to other polymers. The high melting temperature allows the nanofibers to maintain their morphology during the curing process of the

* Corresponding author: cristobal.garcia@strath.ac.uk 
laminate. However, these enhancements which nanofiber interleaving is expected to bring in composite materials still have to be tested and proven desirably using both experiments and FEM numerical analysis.

This work aims to investigate some dynamic properties of nylon nano-modified GFRP composites and their delamination resistance. The dynamical properties are evaluated experimentally using free vibration test and numerically using finite element modelling (FEM). In terms of delamination resistance, the interlaminar strength is determined using ASTM D 2344 international standard test for determining short beam strength of Polymer Matrix Composite Materials and Their Laminates [7]. The results of the latter experiments are also simulated in ANSYS Workbench. The paper offers experimental results which come to verify our FEM models and simulation results. Eventually a discussion on the experimental and the simulation results is proposed. The paper ends with some conclusions and trends for future research in terms of potential applications for the nano-modified composites.

\section{Dynamic behaviour of nylon nano interleaved GFRP laminates}

This section discusses the dynamic behaviour of nylon interleaved composite beams as compared to the traditional composite laminates. The experimental analysis for the virgin and the nano-modified composites was carried out using free vibration tests which are described in subsection 2.1. Consequently the finite element model used to simulate the experiments is introduced. Eventually, the experimental and FE model results are compared and discussed.

\subsection{Experimental investigation}

The vibration properties of composite laminates with and without nylon nanofibers are analysed in this paragraph. The composite specimens tested have the following dimensions $168 \times 32 \times 3 \mathrm{~mm}$ and are fabricated with a symmetric stacking sequence of $[0 / 90 / 0 / 90 / 0]_{s}$. The specimens are composed of 10 GFRP layers. The nylon modified specimens are interleaved with networked membranes of nylon nanofibers into the ply interfaces. The membranes of nylon nanofibers are interleaved at each ply composite interface excluding the central one.

The incorporation of the membrane of nanofibers did not affect the thickness of the composite laminates. Ten specimens made of glass fibre epoxy composite identical in size, number of layers and stacking sequence are tested. Five of these are virgin (non-interleaved) and the other five are nylon modified.

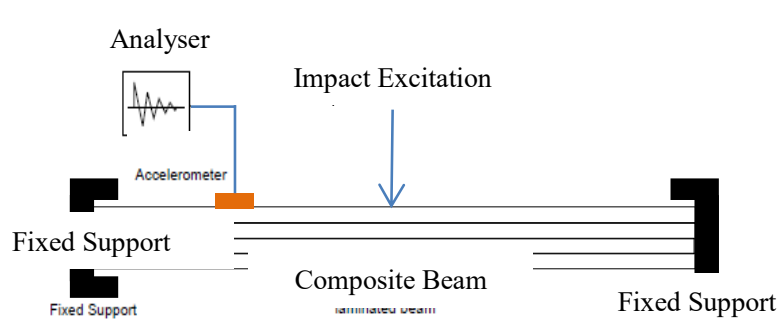

Figure 1: Dynamic free experiment for measuring the vibratory responses of the composites laminated beams

Free vibration tests were carried out with specimens fixed at both ends as indicated in figure 1. An impact excitation was applied at the middle of the composite laminate using a modal hammer. After that, the free decay vibration response of the composites was recorded using a RT-440 portable analyser. The experiments were repeated 10 times for each specimen. The natural frequencies and the damping ratios for each specimen were determined applying the Fast Fourier Transform (FFT) and the Logarithmic decrement method [8, 9] respectively, on the recorded free decay acceleration signals. The presented results are averaged over the tests and the specimens.

\subsection{Numerical modelling}

The finite element model (FEM) used to simulate the dynamic behaviour of the virgin and nylon nanomodified composite laminates was developed using ANSYS Workbench. The free decay time domain signal obtained after the hammer impact was simulated using transient vibration analysis. The number of elements used for each lamina was 936 elements and the criteria employed to select the number of elements was convergence [10]. The element type used was Shell 181 and it was chosen among several elements on the basis of having high accuracy and minimum computations time. Then the simulated free decay response obtained was used to calculate the natural frequencies and the damping ratio. The simulations for the traditional and nano-modified composites beams used the same dimensions, number of layers and ply orientations as those of the experimentally manufactured composite beams (see \&2.1). The glass fibre reinforced polymer (GFRP) composite layers are simulated using the materials constants given in table 1 , where $\mathrm{E}$ is the young modulus, $\mathrm{G}$ is the shear modulus, $\mathrm{v}$ is the poison's ratio and $\rho$ is the density of the material [11]. For the nanomodified composites, as the nylon nanofibers are interleaved at the ply interfaces are embedded into epoxy resin, the material constants are calculated according to the rule of mixture as indicated in reference [12]. The material parameters for the interfaces composed of nylon nanofibers and epoxy resin are also given in table 1 . 
Table 1: Material properties for the layers of GFRP composite material and ply interfaces of nylon nanofibers and epoxy resin

\begin{tabular}{c|ccc}
\hline Magnitude & GFRP layers & Nano interfaces & Units \\
& & & \\
\hline $\mathrm{E}_{1}$ & 44000 & 3000 & $\mathrm{MPa}$ \\
$\mathrm{E}_{2}=\mathrm{E}_{3}$ & 11000 & 750 & $\mathrm{MPa}$ \\
$\mathrm{G}_{12}=\mathrm{G}_{13}$ & 4500 & 800 & $\mathrm{MPa}$ \\
$\mathrm{G}_{23}$ & 500 & 400 & $\mathrm{MPa}$ \\
$\mathrm{v}_{12}$ & 0.28 & 0.35 & dimensionless \\
$\mathrm{V}_{13}=\mathrm{v}_{12}$ & 0.10 & 0.2 & dimensionless \\
$\rho$ & 1085.9 & 1140.0 & $\mathrm{Kg} \mathrm{m}^{-3}$ \\
\hline
\end{tabular}

\subsection{Results and comparison}

Table 2 and 3 shows the first five experimentally measured and numerically calculated natural frequencies for the virgin and the nano-modified composite specimens. In tables 2 and 3 the differences in $\%$ between the frequencies for the virgin and the nanomodified specimens are also indicated. The results indicate that the natural frequencies are not affected by the interleaving with nylon nanofibers. The miniscule changes in the natural frequencies which are below $5 \%$ are within the range of the experimental and measurement error. These very little changes in the frequencies can be explained by the fact that nylon nanofibres have rather low stiffness which is much lower than the stiffness of the glass fibres, and the interleaving did not change the mass of the specimens.

Table 2: Variation of natural frequencies due to nylon nanofibers measured experimentally

\begin{tabular}{c|ccc}
\hline Frequencies & $\begin{array}{c}\text { Virgin } \\
(\mathrm{Hz})\end{array}$ & $\begin{array}{c}\text { Nano-Modified } \\
(\mathrm{Hz})\end{array}$ & $\begin{array}{c}\text { Variation } \\
(\%)\end{array}$ \\
\hline $\mathrm{f}_{1}$ & 484.45 & 498.80 & 2.88 \\
$\mathrm{f}_{2}$ & 930.93 & 965.90 & 3.62 \\
$\mathrm{f}_{3}$ & 1373.75 & 1434.80 & 4.25 \\
$\mathrm{f}_{4}$ & 1857.50 & 1929.00 & 3.71 \\
$\mathrm{f}_{5}$ & 2303.75 & 2399.30 & 3.98 \\
\hline
\end{tabular}

Table 3: Variation of natural frequencies due to nylon nanofibers calculated using FEM

\begin{tabular}{c|ccc}
\hline Frequencies & $\begin{array}{c}\text { Virgin } \\
(\mathrm{Hz})\end{array}$ & $\begin{array}{c}\text { Nano-Modified } \\
(\mathrm{Hz})\end{array}$ & $\begin{array}{c}\text { Variation } \\
(\%)\end{array}$ \\
\hline $\mathrm{f}_{1}$ & 515.00 & 535.00 & 3.74 \\
$\mathrm{f}_{2}$ & 940.00 & 945.00 & 0.53 \\
$\mathrm{f}_{3}$ & 1330.00 & 1343.00 & 0.97 \\
$\mathrm{f}_{4}$ & 1770.00 & 1775.00 & 0.28 \\
$\mathrm{f}_{5}$ & 2420.00 & 2423.00 & 0.12 \\
\hline
\end{tabular}

The damping ratio of the composite laminates with and without nylon nanofibers is also investigated. Table 4 shows the values measured experimentally and calculated numerically using the FE model.

Table 4: Variation in damping ratio due to the interleaving of nylon nanofibers measured experimentally and using FEM

\begin{tabular}{c|ccc}
\hline Damping & Virgin & Nano-Modified & Variation \\
\hline
\end{tabular}

\begin{tabular}{c|ccc}
\hline & (dimensionless) & (dimensionless) & $(\%)$ \\
\hline Experiments & 0.0121 & 0.0165 & 36 \\
FEM & 0.0160 & 0.0233 & 45 \\
\hline
\end{tabular}

Both, the experiments and FEM simulations showed that the interleaving with nylon nanofibers increased the damping significantly with $36 \%$ and $45 \%$ respectively. The higher the damping value the more energy is dissipated; and thus it can be concluded that GFRP composite laminates modified with nylon nanofibers dissipate more energy than virgin ones under the same mechanical conditions. This can be used to reduce the amplitude of vibrations in structures made of such composites. The significant increase in the damping of the nano-modified composites in comparison with traditional ones can be explained by the larger interface area produced due to the incorporation of nanofibers.

\section{Delamination resistance of nylon nano interleaved GFRP laminates}

This paragraph examines the delamination resistance of the nylon-nano modified specimens as compared to the virgin ones. The international standard ASTM D 2344 [13] was performed to experimentally determine the inter-laminar shear strength of the composites. It should be noted that these experiments were simulated using cohesive zone FE modelling via ANSYS Workbench 17.2. The following paragraphs present the experiment performed, the FE modelling and eventually the comparison between the experimental and the numerically obtained results.

\subsection{Experimental study}

Fourteen specimens made of nylon modified composites and virgin laminates were prepared in accordance with the ASTM D 2344 standard. The dimensions of the composite beams were $18 \mathrm{~mm}$ long, $6 \mathrm{~mm}$ wide and 3.21 $\mathrm{mm}$ thick with a stacking sequence of $[0 / 90 / 0 / 90 / 0]_{\mathrm{s}}$ for a total of 10 layers.

The analysis of the inter-laminar shear stress was performed in accordance with the international standard ASTM D-2344 and the experimental test is illustrated in figure 2. The specimens were located on the two $3 \mathrm{~mm}$ diameter supports. During the test, the specimens are loaded in the centre of the beam at a rate of $1.0 \mathrm{~mm} / \mathrm{min}$. The load was increased until each specimen fractured and the fracture load was recorded for each trial. 


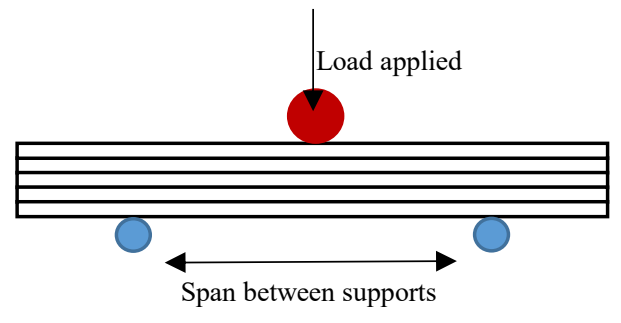

Figure 2: Standard test method to determinate the interlaminar shear strength in composite laminates with and without nylon nanofibers.

After that, the interlaminar shear strength was calculated for each specimen using equation 1 [13], where $\mathrm{F}^{\text {sbs }}$ is the interlaminar strength, $\mathrm{P}_{\mathrm{m}}$ is the fracture load, $b$ is the specimen width and $h$ is the specimen thickness.

$$
F^{s b s}=0.75 \times \frac{P_{m}}{b \times h}
$$

\subsection{Numerical study}

The finite element model used to simulate the experiments was developed using cohesive zone modelling (CZM) in ANSYS Workbench. The CZM used the bi-linear traction separation law. The material properties for the layers of GFRP composite material are given in table 1 . The parameters used to simulate the interfaces of the virgin and the nano-modified composites are given in table 5 , where $\sigma_{\max }$ and $\mathrm{T}_{\max }$ are the maximum normal stress and the tangential traction stress respectively, $\mathrm{u}_{\mathrm{n}}{ }^{\mathrm{c}}$ and $\mathrm{u}_{\mathrm{t}}{ }^{\mathrm{c}}$ denote the normal and the tangential displacement jump at the completion of the debonding, and $\alpha$ is the ratio between the normal displacement jump at maximum traction and at the completion of debonding. The virgin and the nanomodified composite beams were modelled with the same dimensions, number of layers and ply orientations as the experimentally manufactured composite beams.

Table 5: Cohesive zone parameters identified for the interfaces of traditional and nano-modified composite materials

\begin{tabular}{c|ccc}
\hline Parameter & Virgin & Nano-Modified & Units \\
\hline$\sigma_{\max }$ & 70 & 73 & $\mathrm{MPa}$ \\
$\mathrm{T}_{\max }$ & 38 & 49 & $\mathrm{MPa}$ \\
$\mathrm{u}_{\mathrm{n}}{ }^{\mathrm{c}}$ & 0.025 & 0.04 & $\mathrm{~mm}$ \\
$\mathrm{u}_{\mathrm{t}}{ }^{\mathrm{c}}$ & 0.08 & 0.09 & $\mathrm{~mm}$ \\
$\alpha$ & 0.1 & 0.085 & dimensionless \\
\hline
\end{tabular}

\subsection{Results and comparison}

A summary of the experimental results obtained following the ASTM D-2344 standard experiment is presented in table 6 . The experiments showed that the inter-laminar strength for the seven virgin composite specimens was $50.21 \pm 4.05 \mathrm{MPa}$. However, this value increased to $63.81 \pm 2.48 \mathrm{MPa}$ for the nylon nanomodified composite specimens. Thus it can be concluded that the inter-laminar shear strength increased with $27.07 \%$ due to the incorporation of nylon nanofibers.

Table 6: Variation in interlaminar shear strength due to the interleaving of nylon nanofibers measured experimentally by ASTM D-2344 and numerically using FEM

\begin{tabular}{c|ccc}
\hline Interlaminar Strength & $\begin{array}{c}\text { Virgin } \\
(\mathrm{MPa})\end{array}$ & $\begin{array}{c}\text { Nano-Modified } \\
(\mathrm{MPa})\end{array}$ & $\begin{array}{c}\text { Variation } \\
(\%)\end{array}$ \\
\hline Experiments & 50.21 & 63.81 & 27.07 \\
FEM & 54.15 & 65.03 & 20.10 \\
\hline
\end{tabular}

The numerical inter-laminar strengths as per table 6 are $54.15 \mathrm{MPa}$ and $65.03 \mathrm{MPa}$ for the virgin and the nano-modified laminates respectively. The FEM results given show that the presence of nylon nanofibers in the composites increases the inter-laminar strength with $20.10 \%$. According to these results, it can be concluded that the incorporation of nanofibers has a significant impact on the interlaminar strength. According to [14], the increase in interlaminar strength can be explained with the presence of significant bridging phenomena due to the interaction between the epoxy resin and the nylon nanofibers

\section{Conclusions and future research}

In this work, membranes of networked nylon nanofibers were interleaved into the ply-interfaces of GFRP composite laminates with the aim to suppress vibrations and to prevent delamination. For this purpose, experiments and FE simulations analysed the effect of nylon nanofibers on the vibratory behaviour and delamination resistance in terms of the natural frequencies, damping and on the inter-laminar shear strength. On the basis of the experimental and the numerical results, the following conclusion can be drawn:

Nylon nanofibers did not affect the natural frequencies of the nano-modified specimens. The frequencies underwent very small changes which can be considered within the range of the noise and the numerical errors. Thus in terms of frequencies the vibratory behaviour of the nano-modified specimens is the same as the behaviour of the virgin ones. On the other hand the damping ratio considerably increased due to the inclusion of nanofibers according to both the experiments and the numerical modelling. The experimental results showed an increment of $36 \%$ in the damping ratio of the nano-modified specimens while the numerical simulations reported a $45 \%$ increase. From these results it was concluded that nano-modified composite materials dissipate much more energy than virgin ones. This property can be used for purposes of 
reduction of the vibration amplitude which can be achieved by the interleaving with nylon nano-fibres. On the other hand the vibratory behaviour of the nanomodified laminates is not supposed to change in terms of frequencies. As the natural frequencies have not changed and the mass remained unchanged as a result of the nylon nano modification it can be assumed that the stiffness of the nano-modified composites has not undergone significant changes.

In terms of delamination resistance, it can be concluded that GFRP composites interleaved with nylon nanofibers are less prone to delamination than the virgin ones. Both the experimental and FEM results showed a significant increase in the inter-laminar strength. An increment of $27 \%$ in the inter-laminar strength was observed experimentally using the ASTM D 2344 standard as compared to a $20 \%$ increment observed from the numerical results. The increase in the inter-laminar strength can be explained by the presence of significant bridging phenomena between the nanofibers and the composite laminates.

This study suggests a finite element model for the dynamic behaviour of the nano-modified composite laminates. The results of this model can be verified from the corresponding experimental tests with freely vibrating composite specimens. The modelling was also done for the purposes of understanding the vibratory behaviour of nano-modified GFRP laminates as compared to the behaviour of virgin ones. The findings from the modelling regarding the stiffness and the damping are being checked with other experimental methods.

The delamination resistance of the virgin and the nano-modified laminates was tested numerically as well as experimentally using the ASTM D 2344 standard. The goal of this test is to determine the inter-laminar strength which was done according to equation (1). Both the experiments and the FE modelling confirmed the increase of the inter-laminar strength as a result of the modification with nylon nano-fibres. The increase obtained numerically was $20 \%$ which agrees well with the $27 \%$ increase from the experimental study. Thus one can conclude that nylon nano-fibres can be used for improving the delamination resistance of GFRP laminates.

For the future, the authors plan to continue the investigation of interleaving with nylon nanofibers for the purposes of delamination prevention and restriction. In this line an investigation of the effect of nylon nanofibers on the impact resistance of the composite laminates to damage. This will be done experimentally and numerically while in the same time the FEM investigation will be done to bring more understanding about the behaviour of nylon nano-modified GFRP laminates.
This study contributes to the knowledge about the effect of nylon nanofibers in GFRP composite laminates. It gives more insight to the dynamic and vibratory behaviour of such composites. And it draws important conclusions regarding the influence of nylon nanofibrous interleaving on some mechanical and dynamic macro-properties of GFRP laminates.

\section{References}

1. Y.A. Dzenis, D.H. Reneker, Patent, Delamination resistant composites prepared by small fiber reinforcement at ply interfaces, University of Nebraska Lincolm (1999)

2. L. Daelemans, S. Heijden, I. Baere, H. Rahier, W. Paepegem, K. Clerck, $17^{\text {th }}$ European Conference on Composite materials, Increasing the damage resistance of composites by interleaving them with electrospun nanofibrous veils, 1-8 (2016)

3. A. Zucchelli, M.L. Foccarete, C. Gualandi, C. Ramakrishna, J Polym Adv Technol, Electrospun nanofibers for enhancing structural performance of composite materials, 22, 339-349 (2011)

4. H. Saghafi, S.R.Ghaffarian, T.M. Brugo, G. Minak, A. Zucchelli, H.A. Saghafi, J Compos Part B, The effect of nanofibrous membrane thickness on fracture behaviour of modified composite laminatesA numerical and experimental study, 101, 116-123 (2016)

5. C. Garcia, J. Wilson, I. Trendafilova, L. Yang, J Compos Struct, Vibratory behaviour of glass fibre reinforced polymer (GFRP) interleaved with nylon nanofibers, 176, 923-932 (2017)

6. R. Sultan, S. Guirguis, M. Younes, E. El-Soaly, Int J Mech Eng, Delamination identification on composite material by free vibration test, 1, 227-236 (2012)

7. C.A. Berg, J. Tirosh, M. Israeli, Conference of Composite Materials: Testing and Design, Analysis of Short Beam Bending of Fiber Reinforced Composites, ASTM, 206-218 (1972)

8. E. Barkanov, W. Hufenbach, L. Kroll, J Comput Method Appl M, Transient response analysis of systems with different damping models, 192, 33-46 (2003)

9. H. Mevada, P. Dipal, $12^{\text {th }}$ International conference on vibration problems (ICOVP), Experimental determination of structural damping of different materials (2015)

10. K. Alnefaie, J Compos Struct, Finite element modelling of composite plates with internal delamination, 90, 21-27 (2009)

11. H. Saghafi, $\mathrm{PhD}$ thesis, Mechanical behaviour of flat curved laminates interleaved by electrospun nanofibers, University of Bologne (2013)

12. P. Zhu, Z.X. Lei, K.M. Liew, J Compos Struc, Static and free vibration analyses of carbon nanotubereinforced composite plates using finite element method with first order shear deformation plate theory, 94, 1450-1460 (2012) 
13. ASTM Standard, D 2344/D 2344 M, Standard test method for short-beam strength of polymer matrix composite materials and their laminates (2000)

14. R. Palazzetti, I. Trendafilova, A. Zucchelli, J Compos Struc, The self-reinforcing effect of nylon 6,6 nano-fibres on CFRP composite laminates subjected to low velocity impact, 106, 661-671 (2013) 